\title{
COVID-19 Pandemic: Are Caregivers of Family Members with Depression at Risk?
}

\author{
Afifah Idris*, Noremy Md Akhir \\ Centre for Research in Psychology and Human Well-being, Faculty of Social Sciences and Humanities, National \\ University of Malaysia, 43600 UKM Bangi, Selangor, Malaysia. \\ *Corresponding author's email: afifah.idris90@gmail.com
}

\begin{abstract}
More than a year has passed since the first COVID-19 case was detected in Malaysia. The pandemic presents a serious threat to not only physical health, but also mental health. Consequently, the world is dealing with not only the viruses, but also the adverse impacts towards emotional well-being. The restrictions imposed by the government of all countries affected by the pandemic including Malaysia have indirectly and negatively affected the caregivers of family member with depression. Many studies have investigated this issue. However, limited study that focuses on mental health among the caregivers of family members with depression can be found in the Malaysian context. Hence, this article discusses on the relationship between COVID-19 and depression, and the importance of focusing on the effects towards caregivers of family members with depression during the pandemic. Recommendations for future research have also been discussed.
\end{abstract}

Keywords: Pandemic, COVID-19, caregiver, family members, depression

\section{INTRODUCTION}

In December 2019, the first COVID-19 cases were detected in Wuhan, Hubei Province, China, spreading rapidly globally ever since. Within a short time, it has become a global emergency for public health. As of $20^{\text {th }}$ October 2020, there were more than 40 million cases with more than 1 million deaths recorded globally. Health officials worldwide, including the World Health Organization (WHO) and the Center for Disease Control (CDC) have recommended to implement self-quarantine, isolation, and physical distancing to curb the transmission of COVID-19 (Bauer et al., 2020).

These actions have indirectly caused negative effects toward mental health. The pandemic has emotionally impacted everyone, especially those with depression. According to Sigdel et al. (2020), the global crises have caused varying degrees of psychological distress in almost all people, most of whom may improve over time. However, with the temporary lockdown and selfquarantine, affected people may experience adverse emotions, including boredom and loneliness (Brooks et al., 2020). This phenomenon shows that the world is dealing with not only the virus, but also the adverse impacts emotionally. According to the guidelines of
COVID-19 Management by the Ministry of Health Malaysia, the way a person responds to the crisis depends on the individual background and the community he or she lives in. Thus, it is critical for everyone to take care and help each other, especially those whom are emotionally and psychologically affected by the pandemic.

Issues related to depression is not a new topic to be discussed. It is a common mental illness occurring worldwide. Depression has affected more than 264 million people globally, and estimated to be the second highest cause of death in 2020 after cardiovascular disease (WHO, 2020). Coincidently, the pandemic happened. On $24^{\text {th }}$ January 2020, the first COVID-19 case was identified in Malaysia (WHO, 2020). Since then until $11^{\text {th }}$ March 2021, the numbers have increased to 317,717 confirmed cases in Malaysia with 1,191 confirmed death. To prevent the spread of COVID-19, many countries including Malaysia have introduced temporary lockdowns to limit the movement of people and to ensure that people remain safe at home. Based on Chan et al. (2017), while depression has affected nearly 2.3 million people at one time in Malaysia, this problem has not been fully addressed. Currently, the pandemic has been estimated to cause a rise in depression cases. Until 
now, this research subject has had limited publications within the Malaysian context, especially related to the pandemic. The majority of the current research study on depression were conducted on specific subpopulations, such as students, frontliners or communities, but few studies have been done among the caregivers whom have to take care of their family members suffering from depression during the pandemic. To the researcher's knowledge, no such study has been performed in the Malaysian context. Hence, this paper aimed to discuss the issues of depression among caregivers during the prepandemic, psychological stress during the pandemic, and the effects toward caregivers whose family members were suffering from depression during the pandemic.

\section{MENTAL HEALTH IN PRE-PANDEMIC AND DURING COVID-19 PANDEMIC}

\subsection{Depression among caregiver during pre- pandemic}

Taking care of family members suffering from depression or other types of mental illness can cause psychological distress (Coloni-Terrapon et al., 2020; Yee Chin et al., 2018; Jeyagurunathan et al., 2017; Derajew et al., 2017; Cabral et al., 2014). Coloni-Terrapon (2020) asserted that caregivers were socially isolated, lacking social support from other family members and healthcare providers. Furthermore, the caregivers also experienced lower activity levels in their daily life. During the preCOVID-19 pandemic, due to the long-term and uncertain nature of this illness, the caregivers frequently encountered stress. The hospital-centred care change to a community-based one has catalysed this situation. According to Chong and Subramaniam (2014), the community-based treatment is often considered as more humane and therapeutic. However, in practice, things do not go as expected. The society or family members are not prepared and equipped to take care of their mentally ill family members (Chong \& Subramanian 2014). In fact, one study found that the level of depression among caregivers were the same with their care-recipients (Liang et al., 2016).

Depression among caregivers is associated with longer hours that they have to spend in taking care of their ill family members. Derajew et al. (2017) found a highrate prevalence of depression among caregivers, especially when providing care beyond six hours daily and for patients whom have attempted suicide. Other factors contributing to the depression among caregivers were the patient's current depressive episodes, patient's symptoms severity, lower perceived social support, and self-stigma in caregivers (Yee Chin et al., 2018).

It is known that people with better social support will have lower risk of developing depressive episodes (Cabral et al., 2014). Nevertheless, since mental health care services mainly focus on the patient's disease development, caregivers are often overlooked as they struggle to deal with a variety of changes in their home setting, job, recreation, income, and relationship with the patient (Yee Chin et al., 2018). According to Goldmann and Galea (2014), "in disaster research, depression is the second most commonly studied post-disaster mental health condition; however, owing to its large burden in the general population, it may be the most prevalent postdisaster and post epidemic disorder". Thus, it is critical to focus on the mental health of the caregivers as they are also at risks in developing depression and other types of mental illness while caring for their ill family members.

\subsection{Psychological Stress during Covid-19 Pandemic in Malaysia}

On $11^{\text {th }}$ March 2020, WHO declared the coronavirus disease (COVID-19) a global pandemic, prompting several countries to adopt unprecedented lockdown measures to curb the transmission of the novel virus. Malaysia had the first three COVID-19 positive cases on $25^{\text {th }}$ January 2020. In response to the pandemic, Malaysia's Prime Minister issued an unprecedented Movement Controlled Order (MCO) on 16 ${ }^{\text {th }}$ March 2020. Under the Prevention and Control of Infectious Diseases Act 1988 and the Police Act 1967, the order restricts social practices throughout the nation (Wan Mohd Yunus et al., 2021). The temporary lockdown has caused many psychological effects because everyone needs to stay at home, and only one family member (men only/breadwinner) is allowed to go out to buy the necessities for the family. Besides that, people have to be inside the house for 24 hours every day. Surely, this has increased the tension for everyone. The crippling economy has caused millions to lose their jobs and salaries as corporations are ground to a halt. The shift in working environment has also adversely affected some people as they have to work from home. While the purpose of curbing social movement is to protect Malaysians from an infectious and potentially lethal virus, it inadvertently places individuals at risks of mental health deterioration. Those with stable mental state may not be affected. But, what about those who already have pre-existing depression, and the psychological effects of their caregiver during the pandemic?

In Malaysia, a study done by The Center reported that nearly half of the respondents' mental health was negatively affected with varying severity during the MCO. The Centre's survey also showed that after the MCO, $56 \%$ of the respondents were more concerned about their personal finances compared to $47 \%$ during the $\mathrm{MCO}$ as the individuals understood how the economic effects would last beyond the restrictions (Loheswar, 2020). 
A study done in United State of America found that the depression rate after the pandemic began increased 3fold than the pre-pandemic statistics (Ettman et al., 2020). Malaysia is also currently having the same issue. As MCO is still conducted in certain parts of Malaysia, people from the affected state have to bear with the psychological stress. Their social, emotional, and physical well-being has been affected due to the lack of outdoor activities and boredom.

Referring to the 2019 National Health and Morbidity Survey (NHMS), almost 500 thousand people in Malaysia experienced symptoms of depression. With the ongoing pandemic, it was estimated that the depression rate would increase. For instance, in Serdang Hospital, Selangor, a 62-year-old patient admitted due to COVID19 committed suicide due to depression (Elengoe, 2020). Tan Sri Lee Lam Thye, the patron of the Befrienders Kuala Lumpur, asserted that many had been emotionally disturbed by the pandemic and MCO. According to him, although the MCO and RMCO (Recovery Movement Control Order) have improved the situation, the statistics showed that more distressed and suicidal individuals contacted in the months of July until September than in April, May and June 2020 (“Bernama,” 2020).

The MCO was nearly associated with quarantine for everyone since people were not allowed to go out. Thus, while going through the "quarantine" stage, people were more prone to develop psychological distress. Brooks et al. (2020) found that factors contributing to negative psychological effects were frustration, boredom, anger, and others. Therefore, what about the caregivers for family members with depression?

Caregivers need social support so that they can take care of their family members. But, due to the restrictions, they were not the only ones feeling the stress. Here was where the problem began. Mulud and McCarthy (2016) reported that caregiving-related burden was exacerbated by a perceived lack of social support, affecting caregivers' resilience. The caregivers had to bear with the psychological distress, which also affected their selfefficacy and physical health (Yee Chin et al., 2018).

\subsection{The Effects toward Caregiver of Family Member with Depression during Covid-19 Pandemic}

As has been discussed, to date, most of the literature regarding depression due to COVID-19 were done among specific subpopulations or conducted generally towards the community. With the restrictions likely to be extended, caregivers are at risks of developing depression. It has been proven that anxiety and depression are highly associated with caregiving (Park, 2020; Adelman et al., 2014). The pandemic may increase psychological worry and decrease self-care.
The primary caregivers of people with depression face several burdens in their daily life. Before the COVID-19 pandemic, study found that caregivers might face burdens and stressors due to the inadequate support or coping mechanisms, later affecting their life quality and biopsychosocial credibility, and in turn, influencing the treatment they gave (Sharif et al., 2020). Gallagher and Wetherell (2020) affirmed that loneliness majorly contributed to the depression of family caregivers during COVID-19. This situation might be due to the strains over family separation, with some family members being separated in another state due to the border closure.

A team of researchers from University of Pittsburgh, United Kingdom reported that more negative effects from the pandemic were documented by family caregivers than by non-caregivers. The former were more likely to report taking precautions, and worrying about them or their family members getting ill. The situation was likely caused by the increase of caregiving obligations, exacerbated by the pandemic and indirectly causing the care provision to be more complicated mentally, physically, and financially. This situation is a cause for concern when the condition of their family members with depression worsen or relapse due to the pandemic.

Caregivers may undergo greater than normal stress due to several factors. One is due to the cancelled appointments and difficulties in reaching providers. As a result, the communication and coordination with healthcare providers are disrupted (Dang et al., 2020). Research conducted on the experiences of family caregivers of people with mental disorders in Saudi Arabia produced five main themes as follows (Sharif et al. 2020):

\section{Type of care provided;}

2. Challenges encountered;

3. Coping and support mechanism;

4. Caregiver perception of public awareness; and

5. Messages to others.

This study reported that caregivers were psychologically distressed, with an occurrence of mental illnesses, including depression. Thus, caregivers should be identified as a vulnerable group as they are required to give ongoing treatments, affecting their physical and emotional distress, and contributing to substantial stress burden (Gallagher \& Wetherell 2020).

\section{CONCLUSION}

The Director-General of WHO, Dr Tedros Adhanom Ghebreyesus, has stated that the importance of good mental health to the physical health and well-being cannot be overstated. Undoubtedly, COVID-19 pandemic has significantly impacted the society on a local, national, and global scale, and it is yet unclear on 
the end of this pandemic. Caregivers are the backbone for the mental illness patients. However, they have been unnoticed. Just like the mentally ill patients, they too need strong social support by others so that they can maintain their well-being, as well as having a good mental health. Even though the CDC has demarcated several mental health recommendations for those who have been affected, it is unclear on how to better solve psychological issues during a crisis. To the researcher's knowledge, no study has addressed the mental health of the caregivers of family members struggling with depression and other type of mental illness, especially in Malaysia. Hence, future studies focusing on this issue are needed. It is urgent to strategize for psychosocial interventions to reduce psychological distress among caregivers. These interventions will not only fasten the recovery process of their ill family members, but also help maintain the well-being of the caregivers.

\section{AUTHORS' CONTRIBUTIONS}

All authors conceived the presented idea and contributed to the final manuscript.

\section{ACKNOWLEDGMENTS}

I would like to thank Dr. Noremy Md Akhir for her comments on the earlier version of the manuscripts, and for providing insights and expertise that greatly assisted the writing of this article.

\section{REFERENCES}

[1] Adelman, R.D., Tmanova, L.L., Delgado, D., Dion, S. \& Lachs, M. S. 2014. Caregiver burden: A clinical review. Journal of the American Medical Association 311(10), 1052-1060. DOI: http:// doi.org/10.1001/jama.2014.304

[2] Bauer, L.L., Seiffer, B., Deinhart, C., Atrott, B., Sudeck, G., Hautzinger, M., Rosel, I. \& Wolf, S. 2020. Associations of exercise and social support with mental health during quarantine and socialdistancing measures during the COVID-19 pandemic: A cross-sectional survey in Germany. DOI: https://doi.org/ 10.1101/ 2020. 07. 01. 20144105

[3] Brooks, S.K., Webster, R.K., Smith, L. E., Woodland, L., Greenberg, N. \& Rubin, G.J. (2020). The psychological impact of quarantine and how to reduce it: rapid review of the evidence. Lancet 395:912-20. DOI: https://doi.org/10.1016/ S0140-6736(20)30460-8

[4] Cabral, L., Duarte, J., Ferreira, M., \& Santos, C.D. 2014. Anxiety, stress and depression in family caregivers of the mentally ill. Atención Primaria 46: 176-179.
[5] Chan S. L., Hutagalung, F. D., \& Lau P. L. 2017. A Review of Depression and Its Research Studies in Malaysia. International Journal of Education, Psychology and Counseling 2(4), 40-55.

[6] Chong SA, Subramaniam A. 2014. Staying relevant with the times-the changing face of an asylum. Ann Acad Med Singap. 43:481

[7] Coloni-Terrapon C, Favrod J, Clément-Perritaz A, Gothuey I and Rexhaj S. 2020. Optimism and the Psychological Recovery Process Among Informal Caregivers of Inpatients Suffering From Depressive Disorder: A Descriptive Exploratory Study. Front. Psychiatry 10:972. DOI: http://doi.org/10.3389/fpsyt.2019.00972

[8] Dang, S., Penney, L.S., Trivedi, R., Noel, P.H., Pugh, M.J., Finley, E., Pugh, J.A., Houtven, C.H.V. \& Leykum, L. 2020. Caring for Caregivers During COVID-19. Letters to Editor 68(10). DOI: http://doi.org/10.1111/jgs.16726

[9] Derajew, H., Tolessa, D., Feyissa, G. T., Addisu, F., \& Soboka, M. 2017. Prevalence of depression and its associated factors among primary caregivers of patients with severe mental illness in southwest, Ethiopia. BMC Psychiatry, 17(1). DOI: http://doi.org/10.1186/s12888-0171249-7

[10] Elengoe, A. 2020. COVID-19 Outbreak in Malaysia. Osong Public Health and Research Perspective 11(3):93-100. DOI: https://doi.org/ 10.24171/j.phrp.2020.11.3.08

[11] Ettman, C.K., Abdalla, S.M., Cohen, G.H., Sampson, L., Vivier, P.M. \& Galea, S. 2020. Prevalence of Depression Symptoms in US Adults Before and During the COVID-19 Pandemic. JAMA Network Open 3(9). DOI: https://doi.org/10.1001/jamanetworkopen.2020.1 $\underline{9686}$

[12] Gallagher, S. \& Wetherell, M.A. 2020. Risk of Depression in Family Caregivers: Unintended Consequence of COVID-19. DOI: https://doi.org/10.1101/2020.06.15.20131532

[13] Goldmann, E. \& Galea, S. 2014. Mental Health Consequences of Disasters. Annual Review of Public Health 35:169-83. DOI: https://doi.org/10.1146/annurev-publhealth032013-182435

[14] Jeyagurunathan, A., Sagayadevan, V., Abdin, E., Zhang, Y., Chang, S., Shafie, S., ... Subramaniam, M. 2017. Psychological status and quality of life among primary caregivers of individuals with mental illness: a hospital based study. Health and Quality of Life Outcomes, 15(1). DOI: https://doi.org/10.1186/s12955-017-0676-y

[15] Liang, X., Guo, Q., Luo, J., Li, F., Ding, D., Zhao, Q., \& Hong, Z. 2016. Anxiety and depression symptoms among caregivers of care-recipients 
with subjective cognitive decline and cognitive impairment. BMC Neurology, 16(1). DOI: http://doi.org/10.1186/s12883-016-0712-2

[16] Loheswar, R. (2020, April 30). More than half of Malaysians Experience Mental Health Issues during MCO, Study Reveals. Malay Mail: Malaysia.

[17] Mulud, Z.A., \& McCarthy, G. 2016. Caregiver Burden among Caregivers of Individuals with Severe Mental Illness: Testing the Moderation and Mediation Models of Resilience. Archives of Psychiatric Nursing, DOI: http://doi.org/dx.doi.org/10.1016/j.apnu.2016.07. $\underline{019}$

[18] Park, S.S. (2020). Caregivers' Mental Health and Somatic Symptoms during COVID-19. Journals of Gerontology: Social Sciences. Vol. XX, No. XX, 1-6. doi:10.1093/geronb/gbaa121

[19] Sharif, L., Basri, S., Alsahafi, F., Altaylouni, M., Albugumi, S., Banakhar, M., Mahsoon, A., Alasmee, N. \& Wright, R.J. 2000. An Exploration of Family Caregiver Experiences of Burden and Coping While Caring for People with Mental Disorders in Saudi Arabia-A Qualitative Study. International Journal of Environmental Research and Public Health 17(6405). DOI: http://doi.org/10.3390/ijerph17176405

[20] Sigdel, A., Bista, A., Bhattarai, N., Pun, B.C., Giri, G., Marqusee, H. \& Thapa, S. 2020. Depression, Anxiety and Depression-anxiety comorbidity amid COVID-19 Pandemic: An online survey conducted during lockdown in Nepal. DOI: https://doi.org/10.1101/2020.04.30.20086926

[21] Survey finds almost half a Million Malaysians Experience Symptoms of Depression. (2020, October 10). Bernama. Retrieved from https://www.theedgemarkets.com/article/surveyfinds-almost-half-million-malaysians-experiencesymptoms-depression

[22] Wan Mohd Yunus WMA, Badri SKZ, Panatik SA and Mukhtar F. 2021. The Unprecedented Movement Control Order (Lockdown) and Factors Associated with the Negative Emotional Symptoms, Happiness, and Work-Life Balance of Malaysian University Students During the Coronavirus Disease (COVID-19) Pandemic. Front. Psychiatry 11:566221. DOI: https://doi.org/10.3389/fpsyt.2020.566221

[23] WHO. 2020. Covid-19 in Malaysia. Malaysia: World Health Organization.

[24] WHO. 2020. Depression. Geneva: World Health Organization.

[25] Yee Chin Chai, Raynuha Mahadevan, Chong Guan Ng, Lai Fong Chan \& Farahidah Md Dai. 2018. Caregiver depression: The contributing role of depression in patients, stigma, social support and religiosity. International Journal of Social Psychiatry 1-11. DOI: http://doi.org/10.1177/0020764018792585 